tion, fluid balance, the metabolic response to injury, immunology as applied to surgery and shock.

It will obviously be of considerable value for the candidate working for his Primary FRCS but all surgeons will find that they can read this excellent book with both interest and profit.

\section{Pathology of Ischaemic Heart Disease}

By Theo Crawford. Pp. $x+170$, illustrated. Sevenoaks:

The Butterworth Group, 1977. Hard cover $£ 10.50$.

Crossing the hyphen between one discipline and another seems both sensible and fashionable for meetings and symposia at which major problems can be attacked from all angles by experts in the different fields. It cannot be doubted that this is good, and in this book, wherein a single distinguished author whose personal discipline is histopathology writes on ischaemic heart disease from several approaches, we have a rather special example. He starts off with the anatomy of the coronary arteries including the physiology of coronary blood flow, goes on to methods of examination of the coronary arteries in the post-mortem room including radiographic and plastic cast techniques. He then considers the pathogenesis of ischaemic heart disease, the pathology of coronary artery occlusion, the pathology of sudden death and of myocardial infarction and its complications. Next are considered the changes in the blood and biochemistry in ischaemic heart disease and the aetioligical factors ranging from sex and geographical differences through dietary and metabolic theories. The evidence for the incrimination of the major risk factors is not omitted and the author adds his weight to the theory that hard water may play a part in augmenting the incidence of ischaemic heart disease.

This is a short book and easy to read. Although it is primarily intended for the trainee pathologist it will be of equal value to cardiologists and senior students with an interest in cardiology. It is highly recommended as representing not only good value for money but good value in information gained per number of words read.

Peripheral Manipulation (2nd edn).

By G. D. Maitland. Pp. 363, illustrated. Sevenoaks: The Butterworth Group, 1977. Hard cover $£ 13.50$.

The practice of manipulation of both vertebral and peripheral joints has become progressively more widespread in Great Britain over the last decade. The most commonly used techniques are manipulation under anaesthetic or those described by Maitland or Cyriax. Each technique has found its supporters in various quarters and some centres find the methods complementary. The second edition of Maitland's book describing the manipulation of peripheral joints is therefore a welcome companion to the new edition of his better known work on vertebral manipulation.

The book is aimed primarily at the physiotherapist or medical practitioner who wishes to develop his knowledge and skill in the field of manipulation and mobilization of peripheral joints. The basic principle of Maitland's manoeuvres is that repeated gentle oscillatory passive movements can be used to relieve joint pain and stiffness. The first section of the book is devoted to expanding this theory with particular emphasis on examination and repeated assessment of joint range. The second section describes in detail, with the help of simple diagrams, the various methods by which each joint may be mobilized. Finally there is a section on methods of assessment of the treatment and of recording ranges of movement which will appeal to research workers in this field.

The author has purposely avoided discussing diagnosis which will undoubtedly disappoint many medical practitioners especially those in general practice who are often faced not only with the problem of treatment of a painful joint and its surrounding soft tissue but the diagnosis as well.
Controlled studies are obviously still necessary to establish the full value of this form of treatment. Meanwhile, this useful book serves to highlight an aspect of physical treatment for the painful stiff joint and will undoubtedly be very helpful to those already using these techniques or those wishing to start.

Postgraduate Nephrology (2nd edn).

By Roger Gabriel. Pp. 238, illustrated. Sevenoaks: The Butterworth Group, 1978. Limp cover $£ 6.75$.

The major changes in the second edition of Postgraduate Nephrology are the addition of multiple choice questions and case histories now obligatory for all books aimed at the MRCP market.

There are, however, one or two errors of fact such as the statement that renin levels are usually reduced in malignant hypertension and that chlorpropamide is of value in nephrogenic diabetes insipidus. In places, there is a surprisingly dated emphasis, notably when the impression is given that ureterosigmoidostomy is the current operation for bladder replacement. In the discussion of renal artery stenosis there is confusion between the urinary excretion and urinary concentration of substances, and the use of essential and benign interchangeability in hypertension is also odd. The spelling in places is frankly eccentric - one only wishes there were such things as nephrogenic streptococci-unhappily they tend to be nephritogenic.

Nonetheless Dr Gabriel's book is readable and lucid, well organized and balanced, and can be recommended as a primer in nephrology.

Practice. A Handbook of Primary Medical Care. Instalment V Edited by J. Cormack, M. Marinker \& D. MORRELl. London: Kluwer-Harrap Handbooks, 1977. £6.50 per instalment (plus special binder at $£ 1.60$ and postage). Updating service planned to cost about $£ 6.00$ p.a.

With the appearance of the fifth instalment, this handbook is now complete. Many of the problems that arose when parts were missing have now been resolved. This, however, exposes a question which the publishers should consider for the future. Now that the complete handbook is available, who is going to purchase it in instalments?

Every cloud has a silver lining. Some of the best sections of this book are to be found in the later instalments and those who were put off by reading isolated chapters earlier should now reconsider whether they ought not to have this book in their practice library. Its value is not confined only to the doctors in the National Health Service in the United Kingdom. The problems presenting in primary care are the same all over the world. This is equally true for the doctor who calls himself a general practitioner, the family doctor, the internist or the paediatrician. The problems as presented by their patients are the same and so, too, are the ways the doctor should be looking at these.

\section{Recent Advances in Medicine. Number 17}

Edited by D. N. Baron, Nigel Compston \& A. M. DAwson. Pp. 473, illustrated. 1977. Cased edition $£ 12.00$. Soft cover $£ 9.00$.

There are many hours of enjoyable reading amongst the eighteen chapters in the latest Recent Advances in Medicine. None is other than well written, with up to date information and bibliographies. There are some excellent reviews of topics in the main stream of general medicine, such as hepatitis, hyperlipidaemia and cardiovascular disease, bile salts and gall stones, gastro-intestinal hormones, the endocrinology of the hypothalamus and antibacterial chemotherapy. Malignancy gets a generous share, with chapters on epidemiology, Hodgkin's disease, non-Hodgkin's lymphoma and acute 
leukaemia. Other specialist interests are covered by reviews of sexually transmitted disease and glomerulonephritis.

Inevitably, with the growing yield of reports on the results of coronary artery surgery, the chapter on surgery for coronary artery disease is somewhat dated in this respect. It is also perhaps churlish to criticize the chapter on the prostaglandins for missing out one's favourite fields, as of course it could not possibly cover them all. The editors have deliberately interpreted medicine widely - hence additional chapters on the treatment of phobic and obsessional states, slow viruses of the CNS, acclimatization to heat and cold, and infertility.

With so much of more immediate interest to general physicians than, say, obsessional states (which are rare in psychiatric practice), the editors might consider narrowing the range of topic in future editions.

This is a book for the browser and for those wanting reviews of the specific topics. As such it can be warmly recommended.

Recent Progress in Pediatric Endocrinology. Proceedings of the Sereno Symposia, vol. 12

Edited by G. Chiumello \& Z. Laron. Pp. 325, illustrated. London, New York, San Francisco: Academic Press, 1977. £10.00.

The reader who turns to this book for a general review of new developments in paediatric endocrinology will probably be disappointed. Recent Progress in Pediatric Endocrinology records the proceedings of a symposium held in Milan in October 1976. The main themes of the meeting were on carbohydrate metabolism, puberty disorders and hypertension, and guest lectures were combined with shorter communications. Some of the papers will be of general interest, particularly the review of the hormonal control of energy metabolism by Drash, papers on hyperinsulinism in infancy and the long-term effects of hypoglycaemia from Philadelphia and Baltimore, and wise words on delayed puberty by Prader. Dr Maria New's account of her search for an unidentified steroid which causes hypertension and a paper on the possible protective effect of breast feeding in congenital hypothyroidism will also be of interest. However, a fairly high proportion of the thirty-one contributions are short papers describing 'recent results', and this has resulted in the production of an uneven and rather unsatisfactory book.

\section{Studies in Acute Heart Failure}

By Ronald D. Bradley. Pp. 78, illustrated. London: Edward Arnold, 1977. Soft cover $£ 2.95$.

This book reports a collection of observations made in an intensive care unit, into the nature and treatment of heart failure. Much of the theory behind the book lies upon ventricular function curves. In addition to previous work, which has been published, unpublished anecdotes occur throughout the book. On some occasions these have not been critically analysed and correspondingly there is a danger that some dogma may be generated. The reader is taken through the theoretical and practical management and diagnosis of patients presenting in the intensive care unit with heart failure. Correspondingly, this book is essential reading for clinicians involved with the care of the acutely ill patient and also ideally, anaesthetists. This book carefully explains the theory underlying the principles used in practice and often illustrates these points with figures and chest $\mathrm{X}$-rays to exemplify the clinical conditions. The care of the patient after cardio-pulmonary bypass, or the patient with pulmonary embolism with raised pulmonary vascular resistance is dealt with, but only in scant fashion. Also the drug treatment of heart failure, particularly utilizing some of the newer inotropic agents, receives little attention. The reference section is also limited.

This book does not purport to be comprehensive. It should become essential reading to all clinicians involved in the care of the acutely ill patient. I feel sure it will be updated by a more comprehensive further addition.

\section{Notices}

\section{REGIONAL RED CROSS BLOOD BANK GRONINGEN - DRENTHE 3rd Annual Symposium on Blood Transfusion}

A two day meeting on OPEN HEART SURGERY AND BLOOD TRANSFUSION will be held in Groningen, The Netherlands, on October 26 and 27, 1978

Information and registration: Cees Th. Smit Sibinga, M.D., Ph.D., Regional Red Cross Blood Bank, Groningen-Drenthe, Oostersingel 59, Groningen, The Netherlands.

April 27-28, 1979

'OBSTETRIC ANALGESIA AND ANESTHESIA,' to be held at the Colonnade Hotel, Boston, Massachusetts. Sponsored by the Department of Anesthesia, Boston Hospital for Women and Harvard Medical School, Boston, Massachusetts.

This course is designed to present a review and update on obstetric anesthetic management.

Course directors: Gerard W. Ostheimer, M.D. and Milton H. Alper, M.D.

For more information, write: Department of Continuing Education, Harvard Medical School, 25 Shattuck Street, Boston, Massachusetts 02115. 